\title{
ARBRES PER A UNA EDUCACIÓ ARTÍSTICA POSTMODERNA. UN ESTUDI DE CAS A PARTIR DE L'ART CONTEMPORANI
}

\author{
Eloïsa Valero Antón. IES Gabriel Ferrater. Reus
}

\begin{abstract}
La investigació educativa que relatem a continuació parteix d'un enorme interès personal per conèixer millor l'art contemporani i desxifrar-ne els plantejaments i els seus processos de creació, així com el paper que té a la nostra societat. El fet de formar part activa del professorat d'ensenyament secundari ha provocat, de forma inevitable i apassionada, la necessitat d'aprofundir en les relacions entre aquests dos àmbits (art contemporani i educació artística) identificant contrastos i paral-lelismes.
\end{abstract}

Alguns aspectes propis de la societat actual, com l'intens desenvolupament de les tecnologies audiovisuals, la ubiqüitat de la cultura visual, la realitat multicultural, la innovació constant en les concepcions i llenguatges artístics contemporanis..., fan palès el risc que corre el treball a l'aula de quedar desfasat en relació amb la societat. Aquesta investigació parteix de referents contemporanis, procedents de les arts plàstiques i de la cultura visual en general, per establir un procés d'ensenyament i aprenentatge que sigui capaç de posar l'alumnat en relació amb el seu context social i cultural i que, alhora, l'ajudi a desenvolupar estratègies d'interpretació i creació d'acord amb les manifestacions artístiques actuals.

Com que, tal com assenyala Eisner (1998), els estudis de casos individuals es poden generalitzar i aporten una retroalimentació qualitativament diferent a qualsevol programa de formació del professorat (per la seva aplicabilitat directa), hem optat per l'estudi d'un cas concret, concretament el procés d'ensenyament-aprenentatge de l'alumnat de Tècniques d'Expressió Graficoplàstica de l'IES Gabriel Ferrater de Reus durant el curs 2007-08.

Per fonamentar aquest treball hem revisat la literatura relacionada amb l'educació artística postmoderna, les característiques inherents al fet artístic contemporani i els nous currículums i competències bàsiques. El cas desenvolupat en aquesta investigació vol resoldre els dos plantejaments inicials del nou currículum de secundària (DOGC. Decret 143/2007, de 26 de juny), d'una banda posant l'alumnat en relació directa amb el seu entorn natural (els arbres) per començar a treballar (explorar $\mathrm{i}$ percebre; interpretar i crear) i, d'altra banda, proporcionant a l'alumnat criteris per valorar les manifestacions artístiques contemporànies (dimensió social i cultural).

En l'àmbit de les competències, tant pel que fa a les generals com a les pròpies de la matèria d'educació visual i plàstica, hem volgut treballar la competència artística i cultural a través d'un itinerari de referència amb el qual es pugui aprendre a valorar les diferents manifestacions culturals i artístiques. Hem volgut també afavorir el desenvolupament de la competència comunicativa amb relació a temes directament relacionats amb les arts visuals i la natura, des del vessant més científic de l'expressió artística fins al més simbòlic o compromès

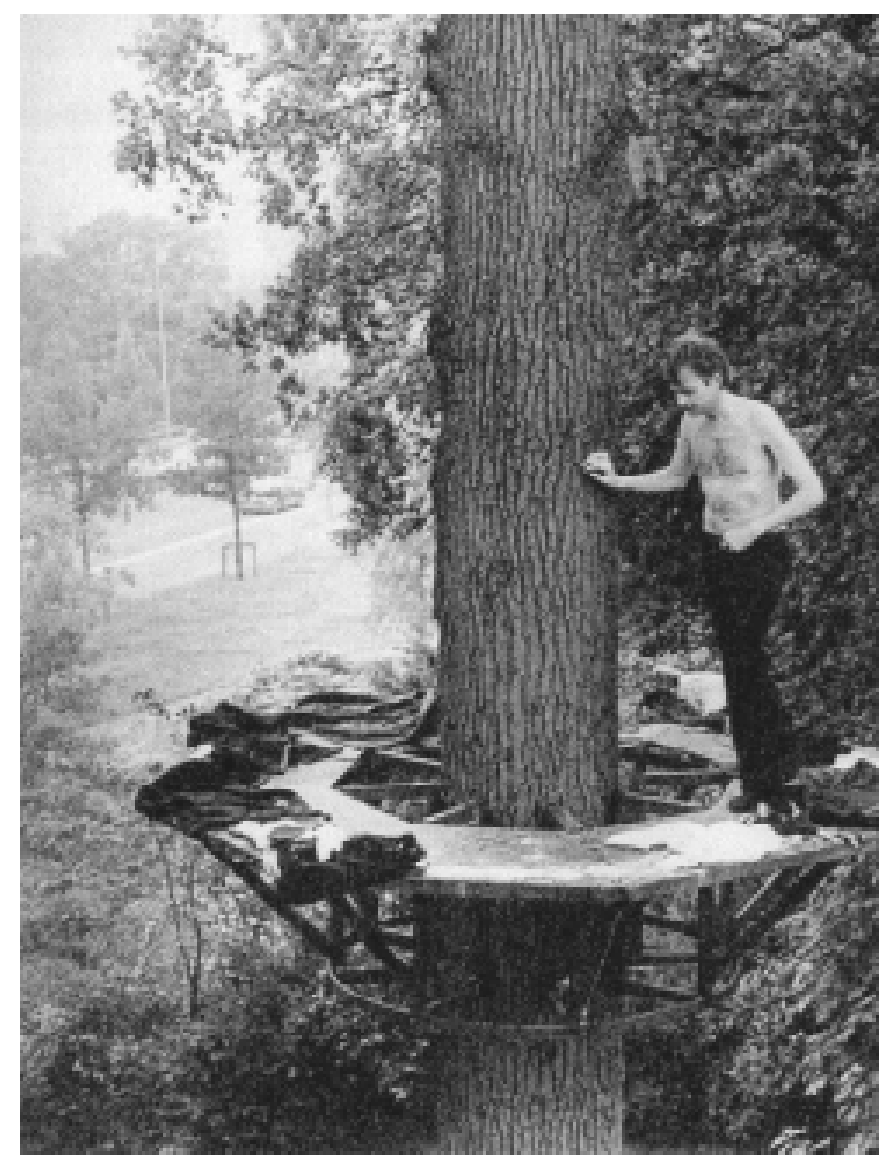

Figura 1. Pepe Espalíu: El niu 


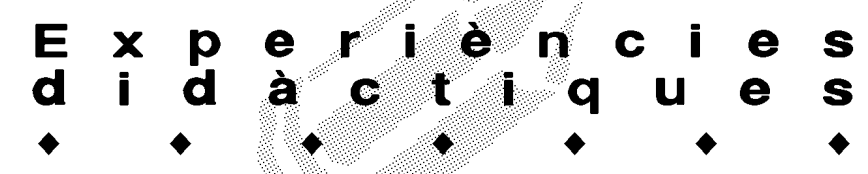

amb l'entorn natural. Amb relació a la competència tècnica i creativa, hem treballat en especial aquelles estratègies creatives afins a les manifestacions artístiques contemporànies.

Les reflexions sobre l'educació artística postmoderna desenvolupades per Efland, Fredman i Stuhr (2003) han estat fonamentals a l'hora d'establir un marc de l'art postmodern, així com per actualitzar el treball a l'aula segons les seves premisses. Podem afirmar que els canvis produïts en les concepcions artístiques més actuals ens proporcionen les pautes a seguir per desenvolupar una educació artística postmoderna.

En establir l'itinerari artístic de referència a partir del qual començar a treballar, hem tingut en compte tant obres d'art contemporani d'artistes de procedències diverses (Joseph Beuys, Ana Mendieta, Giuseppe Penone, Christo, Pepe Espaliú (Fig. 1), Santi Cirugeda, Tim Kwoles, Nils Udo, etc.) com objectes de disseny, còmics, àlbums il.lustrats, cinema, animació, publicitat, etc. En establir el diàleg a classe sobre les imatges, el mateix alumnat ha anat responent les preguntes formulades per arribar, de forma progressiva, a conclusions pròpies. Una de les conclusions a què ha portat aquest diàleg és reconèixer el fet que els nostres referents de la cultura visual es construeixen amb la mateixa retòrica de la imatge (metàfora, ironia, personificació, etc.) que les obres d'art en general. Cal assenyalar també que la predisposició a la intervenció oral durant la classe augmenta en relació amb la proximitat dels referents a la vida quotidiana de l'alumnat.

L'itinerari de referència ens ha servit, abans de classe, per planificar l'experiència didàctica d'acord amb una educació artística postmoderna. Durant la classe: per dialogar sobre les característiques inherents al fet artístic contemporani i els seus contextos socials i culturals. Durant i després de classe: per posar en pràctica activitats artístiques postmodernes.

Cal tenir en compte que el procés d'aprenentatge s'ha produït per descobriment, en introduir l'itinerari de referència un cop avançat el procés creatiu per part de l'alumnat. Això ha permès que els estudiants reconeguessin els propis processos de treball en els utilitzats pels artistes contemporanis, establint-se de seguida una situació de complicitat.

Volem destacar a continuació alguns dels exercicis

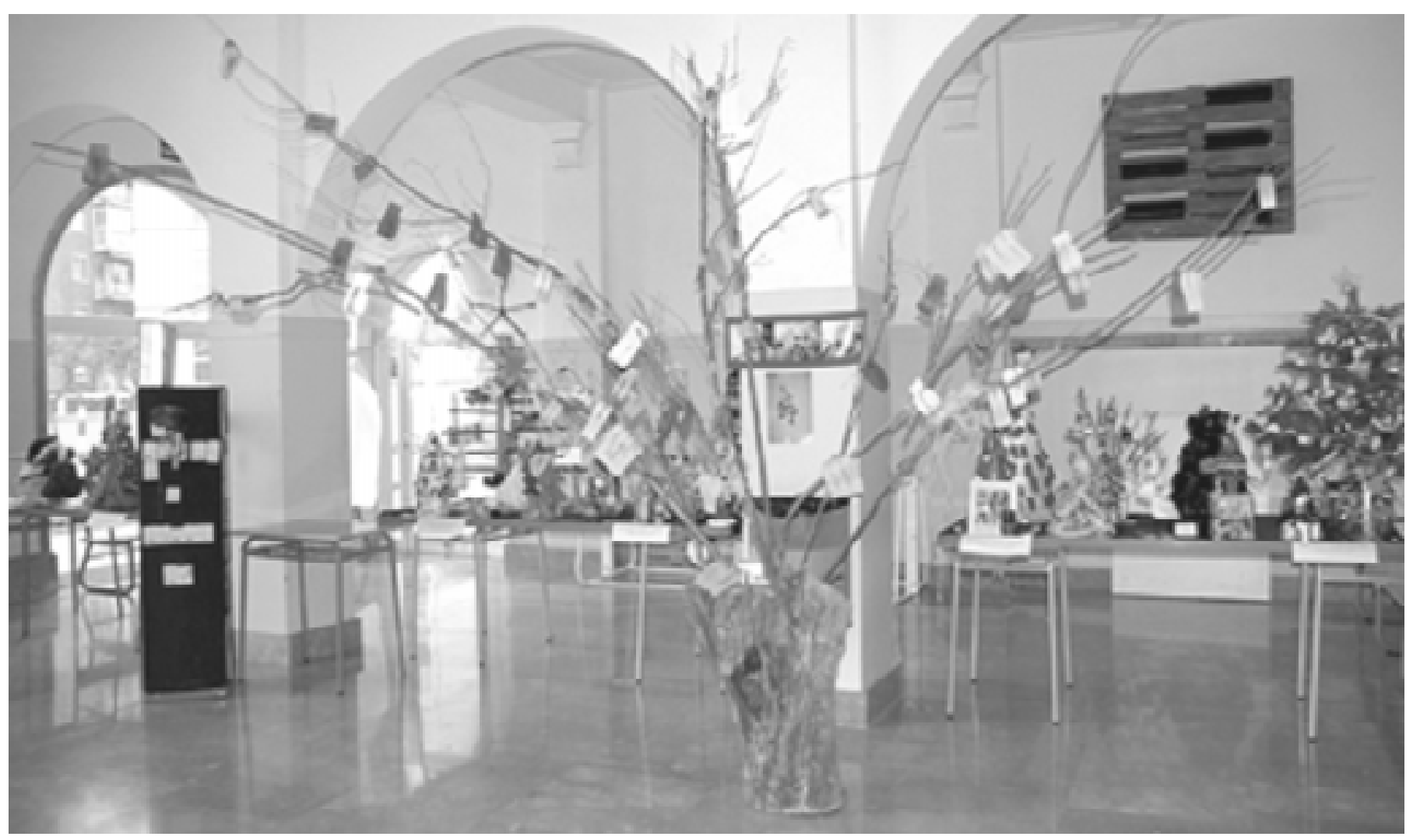

Figura 2. Ainara Garcia: Cupiditas Arboris (soca d'arbre, branques, els desigs per a l'any nou dels companys i companyes escrits sobre cartolines de colors). Tema: L'esperança 


\section{E}

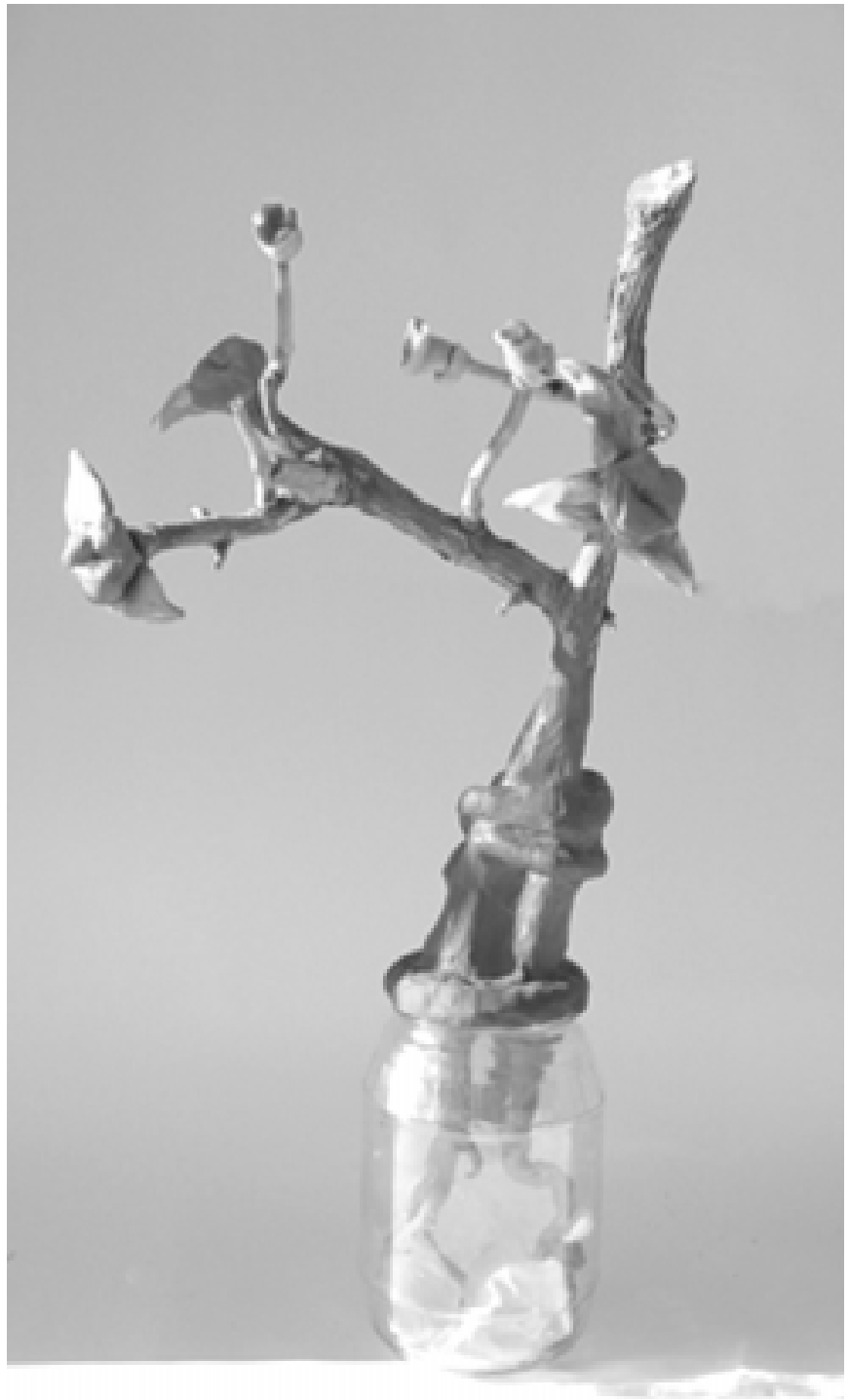

Figura 3. Maria Colom: Abrasarum vulgaris. "Arbre mua" (pot de vidre, plastilina, branquetes). Tema: La recerca de la felicitat.

"Cercada amb deliri, l'Abrasarum, més coneguda com la planta Mua, surt només per Nadal, i ha pogut ser gaudida per molt poca gent. Creix al fons dels armaris més humils, és impossible de ser cultivada, ja que s'alimenta mitjançant les seves gruixudes arrels blau cel, de la il.lusió i l'esperança que crea el Nadal. El tronc d'aquesta es caracteritza per formar unes ones al peu, que suggereixen dos cossos abraçats. Els fruits, seguint la mateixa línia, tenen forma de llavis. EI seu sabor es diu que és el petó més dolç que s'hagi gaudit en el decurs d'una vida. La persona que posseeix la Mua i és capaç de compartir-la amb els seus éssers estimats, també serà capaç de tocar la felicitat, no pas pels girs del destí ni per cops de sort, simplement sabrà gaudir de les petites coses que els altres passen per alt contínuament, dia rera dia, de manera trista però inevitable. Si la planta es ven, els efectes es perden. D'aquesta manera, la seva cerca s'ha convertit en una tradició de cada Nadal, tothom aparca el materialisme i l'ambició per poder així ser la persona que es desitja tant ser. La Mua ens dóna l'únic concepte pur i incapaç de ser transformat". fets a classe que han aconseguit desenvolupar en l'alumnat estratègies de creació d'acord amb les manifestacions artístiques actuals:

Construeix amb la tècnica de l'assemblage el teu arbre de Nadal. Aquesta proposta era una invitació a construir un arbre de Nadal amb materials lliurement escollits per l'alumnat, amb la intenció d'expressar una idea. Molts dels assemblages van resultar ser molt crítics amb el que significa el Nadal a l'actualitat (Fig. 2 i 3).

Demana algú que et faci una fotografia mentre estableixes alguna relació especial amb l'arbre. Aquest exercici formava part de l'exploració inicial de l'arbre escollit i era una invitació a apropar-se a l'arbre no només per representar plàsticament la seva aparença visual, sinó amb la intenció de començar a establir relacions més íntimes o espirituals (Fig. 4).

Utilitza elements de l'arbre com a suport de creació. Aquest exercici donava la possibilitat a l'alumnat de treballar sobre suports alternatius $i$, en aquest cas, tridimensionals, efímers o vulnerables als canvis a través del temps (Fig. 5).

Representa (amb la tècnica o l'instrument que vulguis) algun aspecte no visual de l'arbre. Amb aquesta proposta es convidava a reflexionar sobre la complexitat del fet perceptiu i, en conseqüència, la dimensió multisensorial de l'obra artística. De fet, bona part de l'alumnat va sentir la necessitat d'enregistrar amb mitjans tècnics imatges en moviment dels voltants de l'arbre o bé el so produït per les gotes de pluja sota l'arbre o el cruixit de les branques, etc. (Fig. 6).

Alguns alumnes, com l'Arnau o la Marta, van convidar l'espectador a explorar dimensions gustatives o sonores de l'arbre amb premisses pròpies de l'art d'acció.

Fes una intervenció plàstica a l'entorn. Aquest exer-

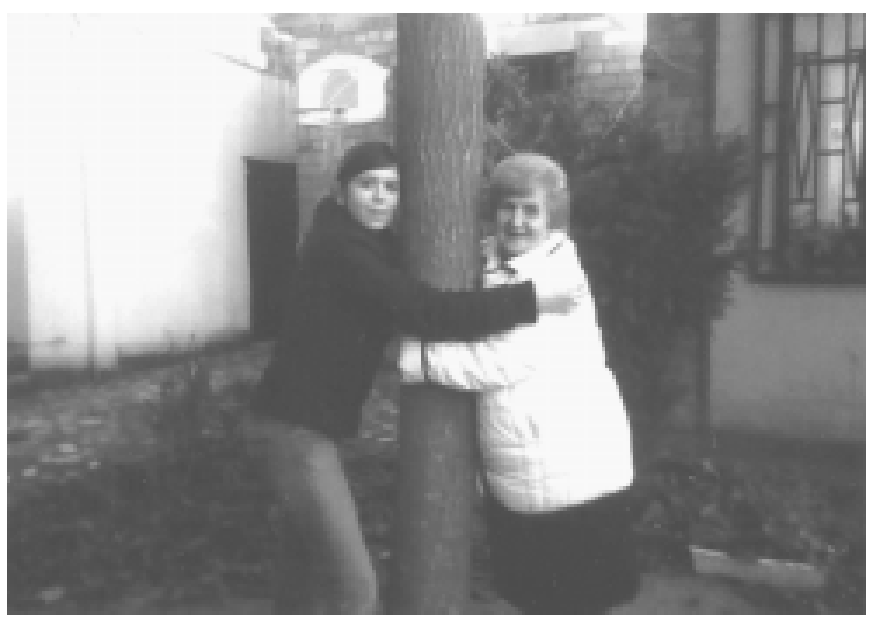

Figura 4. Cristina Magriñá: "La meva àvia diu que si abraces un arbre et dóna energia" 


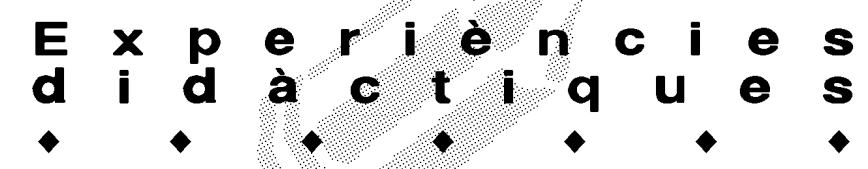

cici proposava canviar els llocs tradicionals d'exposició per altres espais (urbans o naturals) propers a l'alumnat on la interacció amb l'espectador fos directa. Els elements constituius dels espais escollits van esdevenir alhora suports de creació artística.

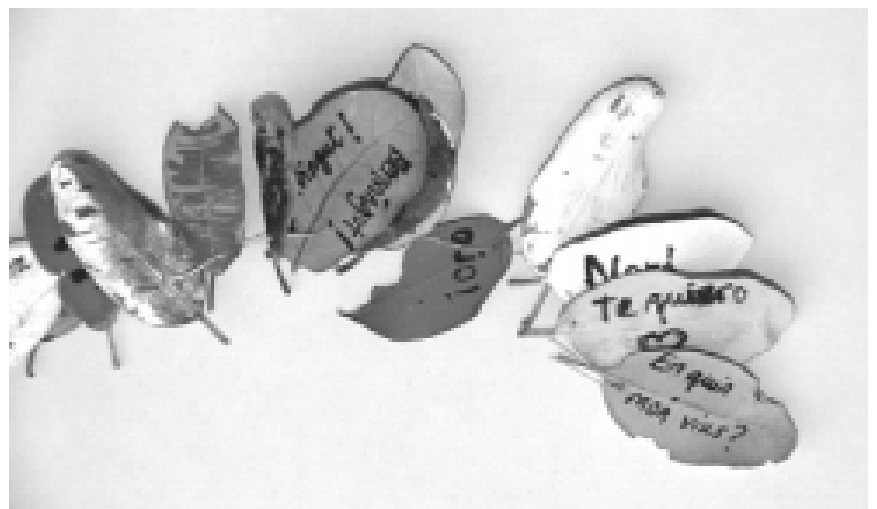

Figura 5. Omar Moreno

En el cas de les intervencions a l'entorn, la participació de l'espectador s'ha concretat en la forma en què s'ha incorporat la intervenció artística a la seva vida quotidiana, com és el cas de la silueta humana pintada pel Rafel i el Jordi simulant l'ombra de l'arbre, que, haventse convertit en un reclam de l'atenció del vianant, ha estat utilitzada per altres ciutadans com a suport publicitari. En aquesta interacció artista (estudiant) i espectador s'ha produït un intercanvi d'opinions i coneixements, fet que ha enriquit ambdues parts, com diu l'Alba sobre el seu treball en grup d'intervenció a l'entorn titulat "Arbres embarassats": "El que em va sorprendre va ser el fet que la gent captava ràpidament la nostra idea, fins $i$ tot més d'un ens va aportar coses noves. Però el que

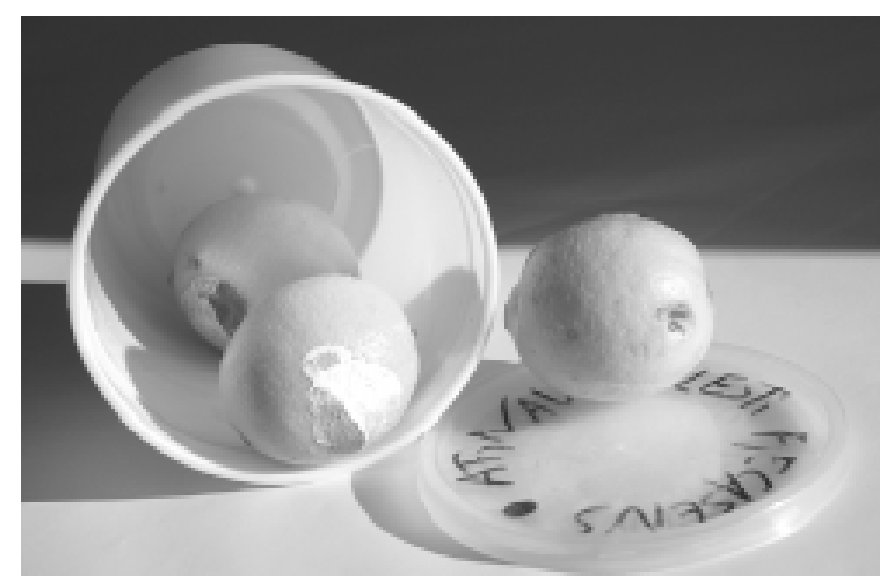

Figura 6. Arnau Olesti: "Veure la llimona amb un 16 escrit, tallar pel mig i olorar" em sembla més curiós és que les dones estaven molt més sensibilitzades amb el nostre treball que no pas els homes, i van ser elles que van dir que els suggeria delicadesa i tendresa, i que els arbres, com les dones embarassades, s'han de respectar" (Fig. 7).

Converteix l'obra d'art en una vivència (art d'acció). Aquest era un treball cooperatiu a desenvolupar en petits grups amb la intenció d'expressar una idea al carrer. Com que era la culminació de tot un procés de treball en relació amb els arbres, molts dels temes escollits van ser en relació amb la natura en general: la importància de l'aigua a les nostres vides, el perill de l'escalfament global, l'intercanvi de gasos que ens faciliten els arbres, etc.

En fer els exercicis d'art d'acció, l'alumnat s'ha documentat sobre temes d'actualitat i ha sortit al carrer per donar a conèixer la seva postura i a increpar la gent a

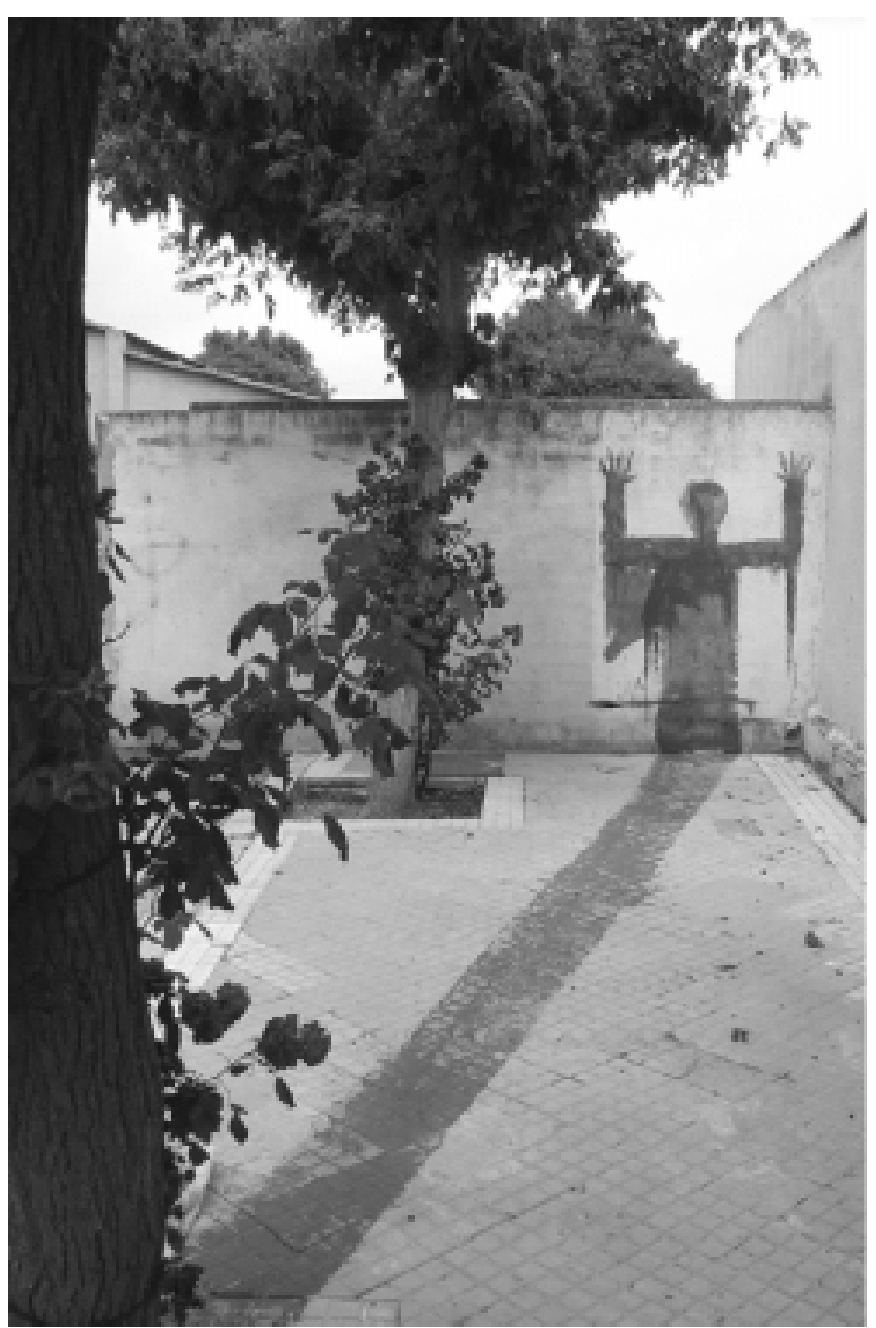

Figura 7. Jordi Sanz i Rafael Arco: Intervenció a l'entorn. Reus, maig 2008. Objectiu: Humanitzar els arbres al voltant de l'institut, dotant-los d'una ombra antropomorfa 


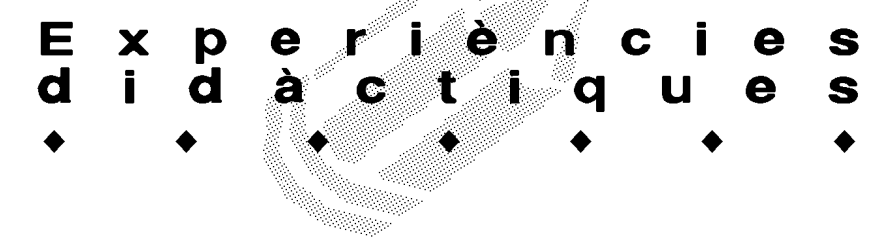

manifestar-se, com diu la Glenda: 'L'art d'acció és una bona manera per fer veure a la gent les coses que vols reivindicar o criticar d'aquesta vida, d'una manera original i peculiar." I la Mireia: "Tots aquests treballs, sobre els arbres i el happening de l'estalvi d'aigua, m'han servit a mi per conscienciar-me realment de la importància vital de cuidar el nostre planeta; a casa meva s'ha implantat una rigorosa llei de reciclatge que fins fa poc tothom es passava pel forro de la jaqueta, però que ara, gràcies als constants crits per veure qui ha llençat la pell de poma a la bossa de plàstics, està donant resultats. També he comprat uns cubells per recollir l'aigua freda de la banyera i sempre intento dutxar-me en el mínim de temps possible. En resum, que estic contenta per estar aprofitant bé allò que el meu planeta em dóna i d'haver pogut fer arribar aquest missatge a d'altres persones" (Fig. 8).

Tal com apunta Maxine Green (2005): "Sens dubte, l'educació ha d'ésser concebuda avui com un mitjà d'obrir el món als judicis crítics del jovent i a les seves projeccions imaginatives i, arribat el moment, a les seves accions transformadores." Una via oberta d'investigació, més enllà de la vinculació de l'art contemporani amb l'educació artística per tal d'actualitzar el treball a l'aula, és la sensibilització artística mediambiental a través de l'art contemporani que, de forma paral.lela, s'ha anat generant durant l'estudi de cas. Tot i que les mostres d'art contemporani vinculades amb la natura, pel seu caràcter efímer, necessiten el suport tecnològic per a la seva difusió i supervivència, fan també una crida a la interrelació amb el medi natural, tan necessària en una societat que ens aparta cada vegada més de l'experiència directa del món. Com diu l'Alfred, "I'olor que desprèn el bosc a primeres hores del matí és impressionant".

La reflexió per afavorir la comprensió dels contextos socials i culturals de l'actualitat s'ha donat en la present investigació, tant en el moment d'apreciar les obres d'art contemporani de l'itinerari de referència, com en el moment de fer els exercicis proposats. Així, per exemple, en la visita a l'exposició de Marina Núñez a La Panera de Lleida, l'alumnat va ser conscient de les vinculacions de les obres d'aquesta artista amb el nostre context social i cultural, tal com es pot apreciar als comentaris després de la visita (Arnau): "La Marina critica durament la desigualtat sexual que es veu cada dia a la nostra societat, la desigualtat de la dona davant de la superioritat imposada- de l'home. D'altra banda, també critica durament la contaminació que diàriament l'home provoca i parla d'una venjança per part de la natura contra l'espècie humana".

En preparar la visita a l'exposició o durant el comentari de les obres de referència, s'ha desenvolupat a clas- se el diàleg sobre temes tan actuals i d'importància cabdal com la necessitat de sensibilització mediambiental, el risc d'intentar assolir el cànon de bellesa estereotipada imposat per la societat de consum, els perills de substituir cada cop més les persones per les màquines, el conflicte de les desigualtats socials o la discriminació per raons de sexe, de religió, etc. Aquest fet ha originat una reflexió sobre la nostra societat i el paper que pot assumir l'art com a generador de canvis socials, com diu l'Arnau: "L'art és un mitjà amb el qual seguir lluitant perquè la gent s'adoni de les realitats socials que l'envolten i convidar-los a lluitar perquè això deixi de ser així".

\section{Referències bibliogràfiques}

EFLAND, A. D., FREEDMAN, K. i STHUR, P. La educación en el arte posmoderno. Edit. Paidós. Barcelona. 2003.

EISNER, E. W. El arte y la educación de la mente: el papel de las artes visuales en la transformación de la conciencia. Edit. Paidós. Barcelona. 2004.

GREENE, M. Liberar la imaginación: ensayos sobre educación, arte y cambio social. Edit. Graó. Barcelona. 2005. Pàg. 92.

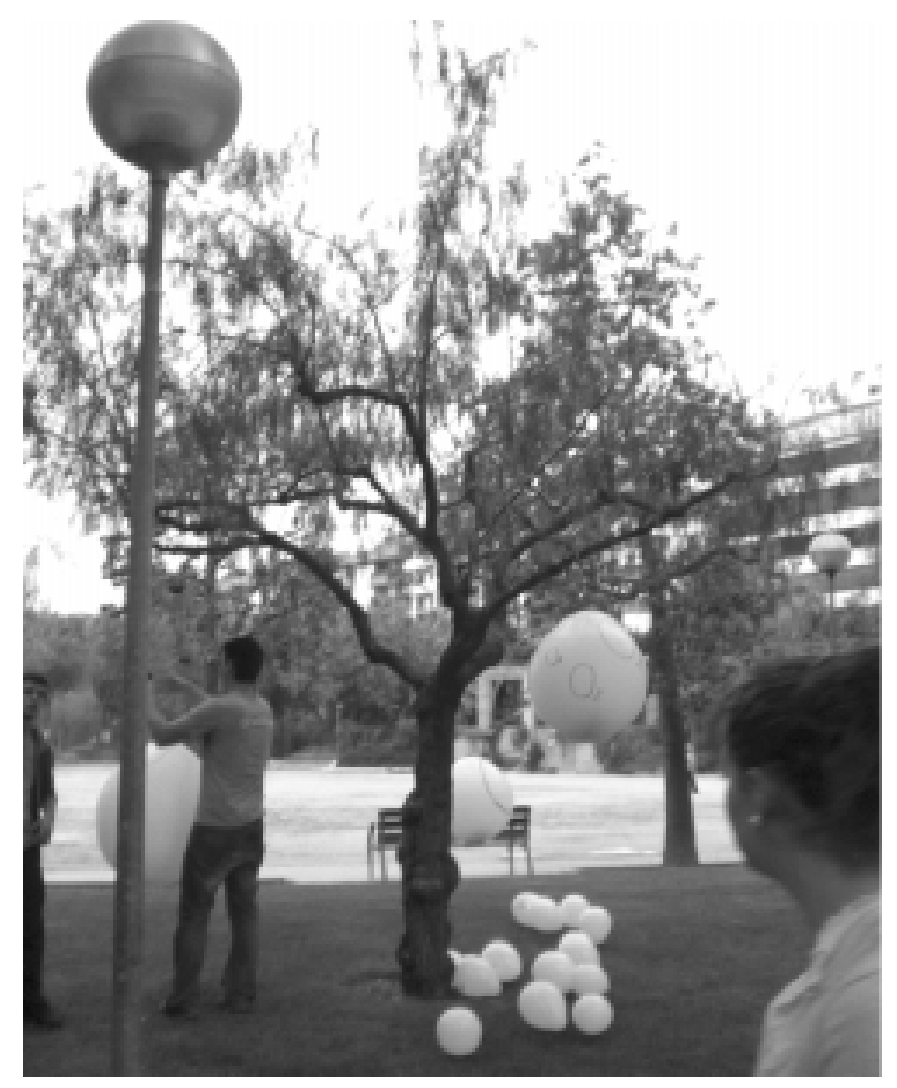

Figura 8. Sònia Blay, Alfred Ferràs, Albert Genovés i Maria Queralt: Happening sobre l'intercanvi de gasos. Reus, maig 2008. Proposta: Incorporar tot un seguit de globus amb el distintiu $\mathrm{O}_{2}$ a un arbre del parc. 